\title{
Psychometric properties of the World Health Organization Quality of Life Instrument-Abbreviated version in Portuguese-speaking adults from three different countries
}

\author{
Propriedades psicométricas do Instrumento de Qualidade de Vida da \\ Organização Mundial de Saúde - Versão Abreviada em adultos falantes de \\ língua portuguesa de três países diferentes
}

\begin{abstract}
Wanderson Roberto da Silva, ${ }^{1}$ Fernanda Salloume Sampaio Bonafé, ${ }^{2}$ João Marôco, ${ }^{3}$ Benvindo Felismino Samuel Maloa, ${ }^{4}$ Juliana Alvares Duarte Bonini Campos ${ }^{1}$
\end{abstract}

\begin{abstract}
Objective: To evaluate the validity, reliability and invariance of the World Health Organization Quality of Life Instrument-Abbreviated version (WHOQOL-Bref) in Portuguese-speaking adults from three different countries.

Methods: A total of 4,020 Brazilian, Portuguese, and Mozambican individuals participated in the study. The total sample was divided into four samples: Brazilian patients $(n=1,120)$, Brazilian students $(n=1,398)$, Portuguese students $(n=1,165)$ and Mozambican students $(n=337)$. Factorial validity of the WHOQOL-Bref was assessed by confirmatory factor analysis. The convergent and discriminant validities of the instrument were assessed using the average variance extracted (AVE) and the square of Pearson's correlational coefficient $\left(r^{2}\right)$, respectively. Composite reliability and ordinal alpha were used as measures of reliability. The metric, scalar, and strict invariance of WHOQOL-Bref was evaluated by multi-group analysis in independent subsamples (within each sample) and only between Brazil and Portugal (transnational invariance), because the configural model of Mozambique was different.

Results: The original model of the WHOQOL-Bref did not show a good fit for the samples. Different items were excluded to fit the instrument in each sample (different models for WHOQOL-Bref among Brazilian, Portuguese, and Mozambican samples). AVE and $\mathrm{r}^{2}$ were not adequate; however, the reliability of the WHOQOLBref was good, except in the Mozambican sample. Invariance was observed only in independent subsamples.

Conclusion: The WHOQOL-Bref fitted models showed adequate factorial validity and invariance in independent subsamples. The transnational non-invariance of the WHOQOL-Bref shows the influence of culture on the operationalization of the quality of life construct.

Keywords: Quality of life, validity, reliability, students, patients.
\end{abstract}

\section{Resumo}

Objetivo: Avaliar a validade, a confiabilidade e a invariância do World Health Organization Quality of Life instrument-Abbreviated version (WHOQOL-Bref) em adultos de três diferentes países de língua portuguesa.

Métodos: Um total de 4.020 indivíduos brasileiros, portugueses e moçambicanos participaram do estudo. A amostra total foi dividida em quatro amostras: pacientes brasileiros $(n=1.120)$, estudantes brasileiros ( $n=1.398)$, estudantes portugueses $(n=1.165)$ e estudantes moçambicanos $(n=337)$. A validade fatorial do WHOQOL-Bref foi avaliada por meio de análise fatorial confirmatória. As validades convergente e discriminante do instrumento foram avaliadas utilizando a variância média extraída (VEM) e o quadrado do coeficiente de correlação de Pearson $\left(r^{2}\right)$, respectivamente. A confiabilidade composta e o coeficiente alfa ordinal foram utilizados como medidas de confiabilidade. As invariâncias métrica, escalar e estrita do WHOQOL-Bref foram avaliadas por análise multi-grupos em subamostras independentes (dentro de cada amostra) e somente entre Brasil e Portugal (transnacional), porque o modelo configuracional de Moçambique era diferente.

Resultados: O modelo original do WHOQOL-Bref não apresentou bom ajustamento para as amostras. Diferentes itens foram excluídos para ajustar o instrumento em cada amostra (modelos diferentes para o WHOQOL-Bref entre amostras brasileiras, portuguesas e moçambicanas). A VEM e o $r^{2}$ não foram adequados; entretanto, a confiabilidade do WHOQOL-Bref foi boa, exceto na amostra moçambicana. A invariância foi encontrada apenas em subamostras independentes.

Conclusão: Os modelos ajustados do WHOQOL-Bref apresentaram adequada validade fatorial e invariância em subamostras independentes. A não invariância transnacional do WHOQOL-Bref revela a influência da cultura na operacionalização do construto qualidade de vida.

Descritores: Qualidade de vida, validade, confiabilidade, estudantes, pacientes.

\footnotetext{
${ }_{1}^{1}$ Departamento de Alimentos e Nutrição, Faculdade de Ciências Farmacêuticas, Universidade Estadual Paulista (UNESP), Araraquara, SP, Brazil. ${ }^{2}$ Departamento de Odontologia Restauradora, Faculdade de Odontologia, UNESP, Araraquara, SP, Brazil. ${ }^{3}$ Centro de Pesquisa William James (WJCR), Instituto Universitário de Ciências Psicológicas, Sociais e da Vida (ISPA), Lisbon, Portugal. ${ }^{4}$ Departamento de Psicologia, Faculdade de Ciências da Educação, Universidade Pedagógica de Moçambique, Maputo, Mozambique.

This article was based on the first author's doctoral dissertation, entitled "Contribuição da imagem corporal, comportamento alimentar e percepção de saúde para qualidade de vida de estudantes universitários - estudo transnacional," presented at Programa de Pós-Graduação em Alimentos e Nutrição, Faculdade de Ciências Farmacêuticas, UNESP, Araraquara, SP, Brazil, and the second author's doctoral dissertation, entitled "Contribuição das variáveis psicológicas na percepção da dor e na qualidade de vida de indivíduos adultos," presented at Programa de Pós-Graduação em Ciências Odontológicas, Faculdade de Odontologia, UNESP, Araraquara, SP, Brazil.

Submitted May 16 2017, accepted for publication Aug 112017.

Suggested citation: Silva WR, Bonafé FSS, Marôco J, Maloa BFS, Campos JADB. Psychometric properties of the World Health Organization Quality of Life Instrument-Abbreviated version in Portuguese-speaking adults from three different countries. Trends Psychiatry Psychother. 2018;40(2):104-113. http://dx.doi.org/10.1590/2237-6089-2017-0058
} 


\section{Introduction}

The concept of quality of life started to be discussed in 1964 by politicians, social scientists, and philosophers who sought to increase the individuals' life expectancy by controlling disease symptoms and decreasing mortality. ${ }^{1,2}$ Thus, the concern with the individuals' quality of life was included in the discussions held by political authorities and doctors, with the aim of developing strategies/actions to promote health and improve the life of the population in general and of patients in particular. ${ }^{3}$ This drove scientists to study this construct under the sponsoring of the World Health Organization (WHO).4,5 In 1995, the Quality of Life Group of the WHO (WHOQOL Group), after several discussions with researchers, doctors, patients, and non-patients, defined quality of life as an "individuals' perception of their position in life in the context of the culture and value systems in which they live and in relation to their goals, expectations, standards and concerns." 3 This concept has been investigated in substantial studies ${ }^{4,6-10}$ and many researchers have highlighted that there are many factors that can influence one's quality of life.

Bullinger et al. ${ }^{11}$ and the WHOQOL Group ${ }^{3}$ reported that the quality of life construct is complex and multidimensional, and its evaluation must include the individuals' perceptions of their feelings, level of independence, health status, routine activities, relationships with the environment, and psychosocial status. Considering these factors, in 1994 the WHOQOL Group proposed a transnational instrument to assess quality of life called the World Health Organization Quality of Life Questionnaire (WHOQOL).

The WHOQOL was developed in collaboration with 15 international centers and comprised 100 questions and 6 factors (physical, psychological, level of independence, social relationships, environment, and spirituality/ religion/personal beliefs). ${ }^{12}$ However, the WHOQOL Group considered that the set of 100 items was too extensive to be used in epidemiological contexts, and therefore proposed a reduced version with 26 items, named World Health Organization Quality of Life Instrument-Abbreviated version (WHOQOL-Bref). ${ }^{13}$ The WHOQOL-Bref was assessed in 20 different countries and considered appropriate to assess the physical, psychological, social relationships, and environmental aspects related to quality of life. ${ }^{13}$ Furthermore, it is important to highlight that the WHOQOL Group recommends including both patients and non-patients as participants in studies using the WHOQOL. ${ }^{3}$

The psychometric properties of the WHOQOL-Bref have thus far been investigated in patients ${ }^{14-16}$ and non- patients ${ }^{8,17-19}$ in almost 40 countries. Some of these studies compared different cultures (transnational studies) and showed different ways of operationalizing the quality of life construct. These transnational studies, including those that used the WHOQOL-Bref, allowed to assess the instrument's structural validity in different social and cultural contexts. Furthermore, in these investigations, the factorial validity and the reliability of the instrument were estimated in each context in order to provide evidence for the operationalization of the construct, and additionally, safe decisionmaking, especially in relation to comparisons between groups. ${ }^{7,20}$

Despite the wide use of the WHOQOL in transnational studies, evaluation of the psychometric properties of the instrument in same-language countries, simultaneously, is unusual. We found only two studies ${ }^{21,22}$ that assessed the instrument in same-language countries. BenítezBorrego et al. ${ }^{21}$ assessed the WHOQOL-Bref in nine different Spanish-speaking countries and showed that the questionnaire's items were interpreted differently according to the culture, i.e., each country had a different way to operationalize the quality of life construct. In turn, Yao and $\mathrm{Wu}^{22}$ compared the Taiwan version of the WHOQOL-100 with the versions used in China and Hong Kong and showed that there are cultural differences among the countries. This type of strategy can be interesting to identify the interference of cultural biases in the construction of the quality of life construct among countries with the same language. Regarding Portuguese speakers, the literature shows some studies ${ }^{23,24}$ that have used the WHOQOL-Bref, but we were not able to find studies involving more than one Portuguese-speaking country simultaneously, aimed to identify the influence of cultural contexts in the construction of the quality of life construct.

Considering the issues above, this study was conducted to assess the psychometric properties of the WHOQOL-Bref when applied to different groups of Portuguese-speaking adult individuals from three different countries.

\section{Method}

\section{Participants}

To achieve the objective of this study, we sought to include Portuguese-speaking individuals from different countries. Among the Portuguese-speaking countries, partner researchers from Portugal and Mozambique agreed to participate. Thus, analyses were performed considering the assessment of the WHOQOL-Bref in different samples. 
The sample of patients were recruited at dental care clinics (radiology, emergency, oral medicine, surgery and traumatology, primary care/prevention, periodontics, endodontics, restorative dentistry, removable partial denture, partial fixed prosthodontics, complete denture prosthodontics, temporomandibular disorders) of Faculdade de Odontologia, Universidade Estadual Paulista (UNESP), Araraquara, state of São Paulo, Brazil. The sample of non-patients comprised college students enrolled in courses of the human, exact and health sciences areas at Brazilian, Portuguese, and Mozambican institutions, as follows: Brazil - UNESP, Campus of Araraquara (Faculdade de Ciências Farmacêuticas, Faculdade de Ciências e Letras, and Instituto de Química); Portugal - Instituto Universitário de Ciências Psicológicas, Sociais e da Vida (ISPA), Faculdade de Ciências Farmacêuticas da Universidade de Coimbra (FFUC), Instituto de Ciências da Saúde Egas Moniz (ISCSEM), Escola Superior de Enfermagem de Lisboa (ESEL), and Instituto Superior de Engenharia do Porto (ISEP); and Mozambique Faculdade de Ciências da Educação, Universidade Pedagógica de Moçambique (FACEP). We have chosen to use college students to form the sample of nonpatients because this strategy has been commonly performed in previous studies. ${ }^{6,14}$ Furthermore, only in Brazil it was possible to include a sample of patients. It should also be clarified that this study used convenience sampling, i.e., participants were chosen based on the researchers' access to both educational (students) and clinical (dental patients) institutions.

The minimum sample size was calculated as proposed by Hair Jr. et al. ${ }^{25}$ Those authors suggested the use of 5 to 10 subjects for each model parameter. Considering 54 parameters in the WHOQOL-Bref model (24 items +24 item errors +6 correlations between factors), the minimum sample size should be from 270 to 540 subjects.

Participation in this study was voluntary, and only those individuals who provided written consent and were over 18 years of age were included. A total of 4,020 individuals, including 1,120 Brazilian dental care patients and 2,900 college students (1,398 Brazilian, 1,165 Portuguese, and 337 Mozambican) agreed to participate in the study.

\section{Sample characterization}

Participants were inquired about age, gender, country, work (yes/no) and socioeconomic stratum. The Brazilian Economic Classification Criteria ${ }^{26}$ were used to estimate the socioeconomic stratum of Brazilian individuals. Self-reported household income was used to investigate the socioeconomic stratum of
Portuguese and Mozambican students. Subsequently, we grouped individuals into economic classes $A(\geq 5$ minimum wages), B (3 to 4 minimum wages), C (1 to 2 minimum wages), and $D$ ( $<1$ minimum wage) according to their monthly household income. This grouping was used to standardize socioeconomic stratum across the samples. It should be noted that the value of the minimum wage is different across the countries (Brazil: 282.84 USD; Portugal: 196.16 USD; and Mozambique: 60.83 USD [2017]) and that this distinction was respected in the present study.

\section{Instrument}

The WHOQOL-Bref was used to evaluate the individuals' quality of life. The instrument comprises 26 items ranked on a 5-point Likert-type response scale. Twenty-four items are divided into four first-order factors, namely physical (item $3=$ pain; $4=$ medication; $10=$ energy; $15=$ mobility $; 16=$ sleep $; 17=$ activities; $18=$ work), psychological (item $5=$ positive feeling; 6 = spirituality; 7 = think; $11=$ body; 19 = esteem; 26 = negative feeling), social relationships (item $20=$ relationships; 21 = sex; 22 = support), and environment (item 8 = safety; 9 = environment; 12 = finances; $13=$ information; 14 = leisure; 23 = home; 24 = services; 25 = transport). The first-order and the second-order factorial models are presented in Figure 1.

Two other items assess overall quality of life (item 1) and general health (item 2); however, these items were not included in the factorial structure of the WHOQOLBref, according to the original model presented by the WHOQOL Group. ${ }^{13}$ Participants answered the Portuguese version of the WHOQOL-Bref. ${ }^{23}$ Detailed information about the process of translation and cultural adaptation of the instrument can be obtained at Fleck et al. ${ }^{4}$

\section{Procedures and ethical aspects}

The clinics at Faculdade de Odontologia (UNESP), and the Brazilian, Portuguese, and Mozambican academic institutions involved in the study approved data collection. Students answered the questionnaire in the classroom, using a self-report format, and patients were interviewed by a psychology professional trained to apply the instrument, in reserved places at the waiting rooms of the clinics. Students were recruited according to the following inclusion criteria: being $\geq$ 18 years old and being enrolled in a higher education institution. Inclusion criteria for patients were: being $\geq$ 18 years old and being a patient in at least one dental clinic. All participants were informed about the aim of the study and signed the informed consent document.

This study was approved by three human research ethics committees. In Brazil, the research was approved 
by the ethics committees of Faculdade de Ciências Farmacêuticas (CAAE no. 29896214.0.0000.5426) and Faculdade de Odontologia (CAAE no. 14986014.0.0000.5416), both from UNESP. In Portugal, the ethics committee of ESEL approved the study (process no. 1413). In Mozambique, FACEP approved the research.

\section{Psychometric analysis}

First, the total sample was divided into four subsamples: a) Brazilian patients; b) Brazilian students; c) Portuguese students; and d) Mozambican students. Second, the psychometric properties of the WHOQOLBref considering the first-order factorial model were assessed in each sample separately. Third, the secondorder factorial model was assessed in all samples (Figure 1). The distribution of responses to the WHOQOL-Bref items in the four samples has shown by descriptive statistics elsewhere. ${ }^{27}$

\section{Factorial validity}

Confirmatory factor analysis (CFA) was used to assess the factorial models of the WHOQOL-Bref. CFA was performed on the polychoric correlation matrix using the weighted least squares means and variance adjusted (WLSMV) method.28 Goodness-of-fit indices, chi-square by degree of freedom $\left(x^{2} / d f\right)$, Tucker-Lewis index (TLI), comparative fit index (CFI), and root mean square error of approximation (RMSEA) were used to assess the model's fit. Marôco ${ }^{27}$ reports that values of $\mathrm{X}^{2} / \mathrm{df} \leq 5.00$, CFI and TLI $\geq 0.90$, and RMSEA $\leq 0.10$ are indicative of an acceptable fit, whereas values of $\mathrm{X}^{2} / \mathrm{df} \leq 2.00$, CFI and TLI $\geq 0.95$ and RMSEA $\leq 0.05$ are indicative of a good fit. The factorial weights $(\lambda)$ of each item were also assessed; when $\lambda<0.30$, the item was excluded. ${ }^{29}$ Furthermore, when the model's fit was poor, modification indices were analyzed. Modification indices were calculated by Lagrange multipliers (LM). Model modifications were performed when LM > 11.27
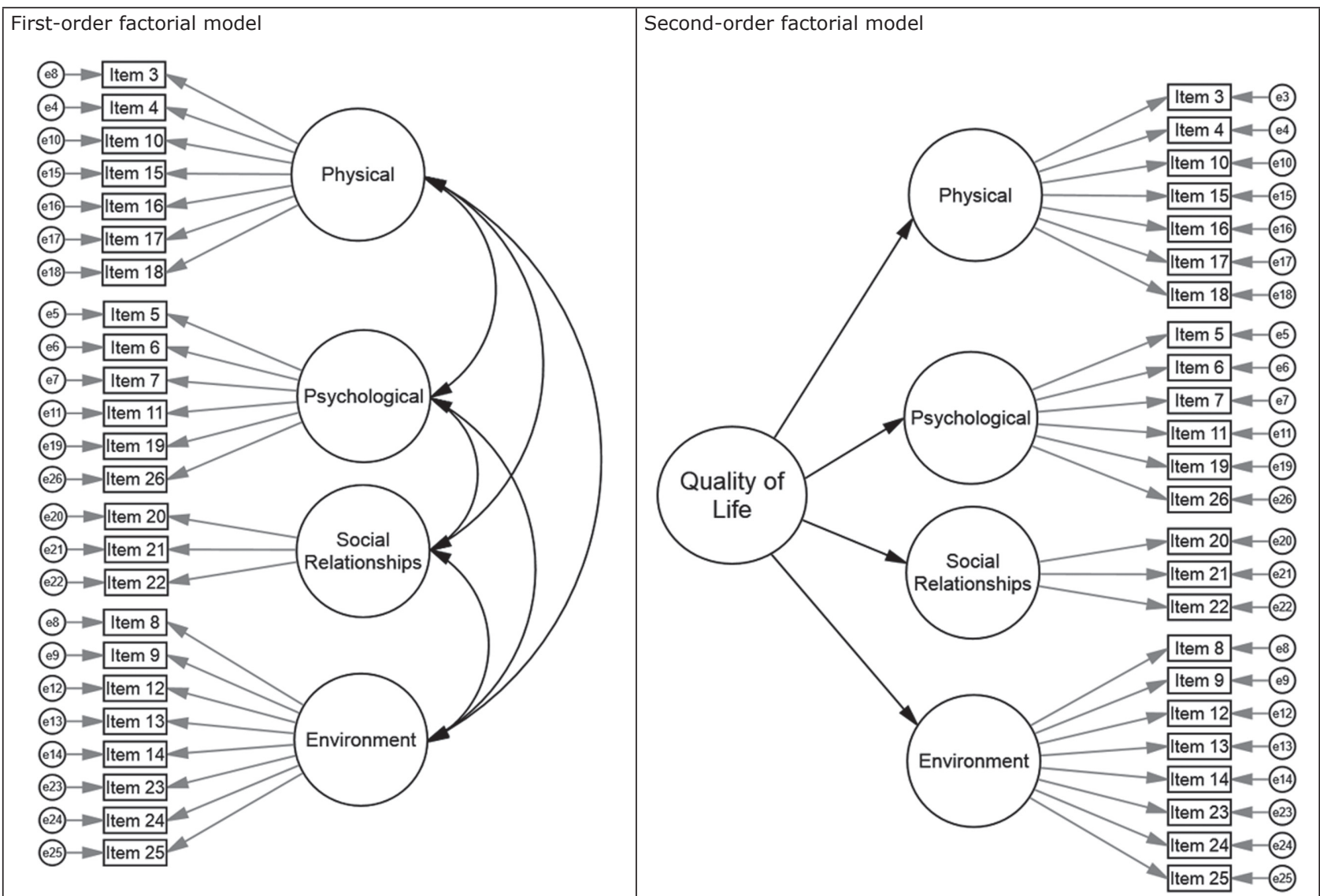

Figure 1 - Models tested for the World Health Organization Quality of Life instrument-Abbreviated version (WHOQOL-Bref). e = error. 
Analyses were performed using the MPLUS software version 7.2.

\section{Convergent validity}

We calculated the average variance extracted (AVE) to evaluate the behavior of the items in each corresponding factor. ${ }^{30}$ AVE values $\geq 0.50$ were considered indicative of adequate convergent validity. ${ }^{25,27,30}$

\section{Discriminant validity}

Discriminant validity was assessed by means of correlational analysis between factors. According to Fornell \& Larcker, ${ }^{30}$ when AVEs of both correlated factors are greater than or equal to the square of the correlation $\left(r^{2}\right)$ between these factors, there was discriminant validity.

\section{Reliability}

Reliability of the WHOQOL-Bref was assessed by composite reliability (CR) and ordinal alpha (a). CR was estimated as proposed by Fornell \& Larcker. $^{30}$ In turn, ordinal alpha values (a) were estimated as proposed by Gadermann et al., 31 using polychoric correlation matrices. Values of $\mathrm{CR}$ and $\mathrm{a}>0.70$ were considered adequate. ${ }^{27,32}$

\section{Invariance}

The invariance test of the fitted models of the WHOQOL-Bref was performed using a first-order structure and divided into two steps, as follows:

- Step 1 - Factorial invariance was assessed in independent subsamples (within each sample). Therefore, all samples were divided randomly into two parts called test and validation (Brazilian patients - test: $n=560$, validation: $n=560$; Brazilian students - test: $\mathrm{n}=699$, validation: $\mathrm{n}=699$; Portuguese students - test: $\mathrm{n}=582$, validation: $n=583$; and Mozambican students - test: $n=168$, validation: $n=169$ ).

- $\quad$ Step 2: Transnational invariance was assessed between Brazilian and Portuguese students. It is important to highlight that the WHOQOLBref showed a different configural model for the Mozambican sample (i.e., the items that remained in the Mozambican model were different from the Brazilian and Portuguese models); therefore, it was not possible to test the invariance of this country with the two others.

The invariance test was performed by multi-group analysis using the chi-square difference $\left(\Delta x^{2}\right)$. Invariance was supported by non-significance $(p>0.05)$ of the chi-square difference test. Partial and total invariance were observed considering: 1) equivalent factor weights (metric invariance $[\lambda]$ ); 2 ) equivalent intercepts (scalar invariance [Int]); and 3 ) equivalent residual variance/ covariance (strict invariance [Cov]). 27,33

\section{Results}

Overall, 2,707 women (67.3\%) and 1,313 men $(32.7 \%)$ participated in the study (Brazilian patients: females $=886[79.1 \%]$, males $=324[20.9 \%]$; Brazilian students: females $=850[60.8 \%]$, males $=$ 548 [39.2\%]; Portuguese students: females $=756$ [64.9\%], males $=409$ [35.1\%]; Mozambican students: females $=215[63.8 \%]$, males $=122$ [36.2\%]). Mean age in the total sample was 26.8 years (standard derivation $[S D]=10.3$; Brazilian patients: mean $=$ 38.6, SD $=10.8$; Brazilian students: mean $=21.2$, SD = 3.7; Portuguese students: mean $=21.5$, SD $=4.1$; Mozambican students: mean $=29.4, \mathrm{SD}=7.9$ ).

Most Brazilian and Portuguese students (2,061 [71.3\%]) did not work (Brazil: 983 [70.5\%]; Portugal: 957 [82.1\%]); most Brazilian patients and Mozambican students worked (patients: 872 [77.9\%]; Mozambican students: 212 [62.9\%]). Furthermore, we found that most Brazilian students ( $n=733$ ) were in economic class B, while Portuguese $(n=518)$ and Mozambican ( $n$ $=124)$ students and Brazilian patients $(n=601)$ were in economic class $\mathrm{C}$. Table 1 shows the distribution of responses to WHOQOL-Bref items in all samples. Table 2 shows the indicators used to evaluate the psychometric properties of the WHOQOL-Bref in all samples.

The first-order factor of the WHOQOL-Bref (original model) did not show a good fit for the study samples; therefore, this model was refined. To obtain an acceptable fit of the first-order factorial model to the sample of patients, items 8 (safety) and 15 (mobility) were excluded, since their error strongly correlated with errors from other items, suggesting a lack of discrimination and convergence of these items. Additionally, one correlation was permitted between items 3 (pain) and 4 (medication), because they showed $L M=238.13$. For the samples of Brazilian and Portuguese students, items 3, 4, 8 and 15 were excluded to obtain an acceptable fit of the first-order factorial model. For the sample of Mozambican students, items 3, 4, 9 (environment) and 26 (negative feeling) were excluded because they had low factorial weights. Furthermore, items 8 and 11 (body) were also excluded from the Mozambican model because they made the model's fit difficult. After the models' refinement, all samples, including subsamples (test and validation) fitted in the first- 
order factorial model. When the fitted models were assessed with the second-order factorial model, we also observed good fits for all samples.

Most values found for AVE and $r^{2}$ were not adequate, showing lack of convergent and discriminant validity of the WHOQOL-Bref factors, respectively (Table 2). The environment factor showed the lowest AVE values in most samples, and good AVE values were observed only for the social relationships factor, except in the Mozambican sample. The smallest correlations were found among the physical and social relationships factors in the samples of Brazilian patients, Brazilian students, and Portuguese students. Furthermore, the environment factor showed low correlations with the other factors. The reliability of the WHOQOL-Bref was adequate in all factors for the samples of Brazilian patients, Brazilian students and Portuguese students.

Table 2 shows the factorial invariance in independent subsamples (test vs. validation) and the transnational invariance between Brazilian and Portuguese students. When the test was performed with independent subsamples, we observed that the fitted models of the WHOQOL-Bref showed metric, scalar and strict invariance (strong) for all samples. Regarding the transnational invariance, the fitted model of the WHOQOL-Bref was not invariant $(p<0.05)$.

\section{Discussion}

In this study, we analyzed the psychometric properties of the WHOQOL-Bref in samples of Portuguese-speaking adults of three different countries spanning three different continents. Although the three countries speak the same language (Portuguese), we found different configural structures of the WHOQOLBref among Brazilian, Portuguese, and Mozambican samples. These results show that the quality of life assessed by the WHOQOL-Bref can be influenced by the cultural context. Furthermore, we observed that some WHOQOL-Bref items correlate with many other items and with other factors, which compromised its convergent and discriminant validities. Therefore, we should highlight in this study the need to carefully evaluate the structural model of the WHOQOLBref before assessing the quality of life of Brazilian,

Table 1 - Distribution of responses to the items of the World Health Organization Quality of Life Instrument-Abbreviated version (WHOQOL-Bref) in different samples

\begin{tabular}{|c|c|c|c|c|c|c|c|c|c|c|c|c|c|c|c|c|c|c|c|c|c|c|c|c|}
\hline \multirow[b]{2}{*}{ Sample/measure } & \multicolumn{24}{|c|}{ Item* } \\
\hline & 3 & 4 & 5 & 6 & 7 & 8 & 9 & 10 & 11 & 12 & 13 & 14 & 15 & 16 & 17 & 18 & 19 & 20 & 21 & 22 & 23 & 24 & 25 & 26 \\
\hline \multicolumn{25}{|l|}{ Brazilian patients } \\
\hline $\mathrm{Me}$ & 3.2 & 3.2 & 3.5 & 4.0 & 3.6 & 3.6 & 3.7 & 3.5 & 3.7 & 2.7 & 3.6 & 3.0 & 3.8 & 3.5 & 3.6 & 3.6 & 3.6 & 3.7 & 3.6 & 3.7 & 3.8 & 3.1 & 3.5 & 3.6 \\
\hline Med & 3.0 & 3.0 & 4.0 & 4.0 & 4.0 & 4.0 & 4.0 & 4.0 & 4.0 & 3.0 & 4.0 & 3.0 & 4.0 & 4.0 & 4.0 & 4.0 & 4.0 & 4.0 & 4.0 & 4.0 & 4.0 & 3.0 & 4.0 & 4.0 \\
\hline Mo & 3.0 & 4.0 & 4.0 & 4.0 & 4.0 & 4.0 & 4.0 & 4.0 & 4.0 & 3.0 & 4.0 & 3.0 & 4.0 & 4.0 & 4.0 & 4.0 & 4.0 & 4.0 & 4.0 & 4.0 & 4.0 & 4.0 & 4.0 & 4.0 \\
\hline SD & 1.2 & 1.2 & 1.0 & 0.9 & 0.9 & 0.9 & 0.8 & 0.9 & 1.0 & 1.0 & 0.9 & 1.0 & 0.8 & 1.0 & 0.9 & 0.9 & 1.0 & 0.9 & 1.0 & 0.9 & 0.9 & 1.1 & 1.0 & 1.0 \\
\hline \multicolumn{25}{|l|}{ Brazilian students } \\
\hline $\mathrm{Me}$ & 4.1 & 4.3 & 3.8 & 3.9 & 3.4 & 3.4 & 3.4 & 3.4 & 3.6 & 3.2 & 3.9 & 3.3 & 4.1 & 3.0 & 3.3 & 3.4 & 3.4 & 3.8 & 3.6 & 3.9 & 3.9 & 3.4 & 3.2 & 3.4 \\
\hline Med & 4.0 & 5.0 & 4.0 & 4.0 & 3.0 & 3.0 & 3.0 & 3.0 & 4.0 & 3.0 & 4.0 & 3.0 & 4.0 & 3.0 & 3.0 & 4.0 & 4.0 & 4.0 & 4.0 & 4.0 & 4.0 & 3.0 & 3.0 & 4.0 \\
\hline Mo & 5.0 & 5.0 & 4.0 & 4.0 & 4.0 & 3.0 & 3.0 & 3.0 & 4.0 & 3.0 & 4.0 & 3.0 & 4.0 & 4.0 & 4.0 & 4.0 & 4.0 & 4.0 & 4.0 & 4.0 & 4.0 & 4.0 & 4.0 & 4.0 \\
\hline SD & 0.9 & 0.9 & 0.8 & 0.9 & 0.8 & 0.8 & 0.8 & 0.8 & 1.0 & 0.9 & 0.7 & 0.9 & 0.8 & 1.1 & 0.9 & 0.9 & 0.9 & 0.9 & 1.0 & 0.9 & 0.9 & 1.0 & 1.2 & 1.0 \\
\hline \multicolumn{25}{|l|}{ Portuguese students } \\
\hline $\mathrm{Me}$ & 4.0 & 4.4 & 3.8 & 4.1 & 3.6 & 3.6 & 3.6 & 3.6 & 3.8 & 3.5 & 3.9 & 3.4 & 4.4 & 3.2 & 3.8 & 3.7 & 3.7 & 4.0 & 3.7 & 4.0 & 4.1 & 3.9 & 3.8 & 3.7 \\
\hline Med & 4.0 & 5.0 & 4.0 & 4.0 & 4.0 & 4.0 & 4.0 & 4.0 & 4.0 & 3.0 & 4.0 & 3.0 & 5.0 & 3.0 & 4.0 & 4.0 & 4.0 & 4.0 & 4.0 & 4.0 & 4.0 & 4.0 & 4.0 & 4.0 \\
\hline Mo & 5.0 & 5.0 & 4.0 & 4.0 & 4.0 & 4.0 & 4.0 & 3.0 & 4.0 & 3.0 & 4.0 & 4.0 & 5.0 & 4.0 & 4.0 & 4.0 & 4.0 & 4.0 & 4.0 & 4.0 & 4.0 & 4.0 & 4.0 & 4.0 \\
\hline SD & 1.0 & 0.9 & 0.8 & 0.8 & 0.8 & 0.8 & 0.7 & 0.8 & 0.9 & 0.9 & 0.7 & 0.9 & 0.8 & 1.0 & 0.8 & 0.8 & 0.8 & 0.8 & 1.0 & 0.8 & 0.8 & 0.9 & 1.0 & 0.9 \\
\hline \multicolumn{25}{|l|}{ Mozambican students } \\
\hline $\mathrm{Me}$ & 3.7 & 3.6 & 3.5 & 3.7 & 3.5 & 3.4 & 3.1 & 3.5 & 3.7 & 2.5 & 2.9 & 2.8 & 3.5 & 3.3 & 3.5 & 3.6 & 3.7 & 3.7 & 3.6 & 3.5 & 3.3 & 3.0 & 2.5 & 3.7 \\
\hline Med & 4.0 & 4.0 & 4.0 & 4.0 & 4.0 & 3.0 & 3.0 & 3.0 & 4.0 & 3.0 & 3.0 & 3.0 & 4.0 & 4.0 & 4.0 & 4.0 & 4.0 & 4.0 & 4.0 & 4.0 & 3.0 & 3.0 & 2.0 & 4.0 \\
\hline Mo & 5.0 & 5.0 & 4.0 & 4.0 & 4.0 & 3.0 & 3.0 & 3.0 & 5.0 & 3.0 & 3.0 & 2.0 & 4.0 & 4.0 & 4.0 & 4.0 & 4.0 & 4.0 & 4.0 & 4.0 & 4.0 & 3.0 & 2.0 & 4.0 \\
\hline SD & 1.1 & 1.2 & 0.9 & 1.0 & 0.9 & 0.9 & 0.9 & 1.0 & 1.2 & 1.1 & 0.9 & 1.0 & 0.9 & 1.0 & 1.0 & 1.0 & 1.0 & 1.1 & 1.1 & 1.1 & 1.1 & 1.1 & 1.2 & 0.9 \\
\hline
\end{tabular}

Me = mean; Med = median; Mo = mode; SD = standard deviation.

* Content of items: 3 = pain, $4=$ medication, $5=$ positive feeling, $6=$ spirituality, $7=$ think, $8=$ safety, $9=$ environment, $10=$ energy, $11=$ body, $12=$ finances, 13 = information, $14=$ leisure, $15=$ mobility, $16=$ sleep, $17=$ activities, $18=$ work, $19=$ esteem, $20=$ relationships, $21=$ sex, $22=$ support, $23=$ home, 24 = services, 25 = transport, 26 = negative feeling. 
Portuguese, and Mozambican individuals, considering the cultural differences in each country.

Evaluation of quality of life using the WHOQOLBref is commonly reported in the literature, $7,9,10,13,16,18,34$ because this instrument is short and recommended by the WHO. ${ }^{13}$ The CFA showed that the original model of the WHOQOL-Bref did not show good fit to the study samples, and some modifications were performed. These modifications included both the exclusion of different items in each sample and insertion of correlations between item errors. One possible explanation for different factorial models among the samples may be culture, which is an important aspect of quality of life. It should be clarified that the refinement of the WHOQOLBref (i.e., items were excluded and correlations between item errors were permitted) was performed to the specific samples assessed in the present study; therefore, such adaptations should not be replicated in other samples. Thus, these fits do not indicate in any way that the instrument has shortcomings, but rather that the WHOQOL-Bref was adapted to fit our samples.

Najafi et al. ${ }^{35}$ deleted some WHOQOL-Bref items to improve the fit of the instrument to the sample assessed. In another study, Najafi et al. ${ }^{17}$ highlighted that the content of item 8 was not clear. The WHOQOL Group, ${ }^{13}$ Fu et al., ${ }^{8}$ and Yoshitaki et al. ${ }^{16}$ also performed some fits in the WHOQOL-Bref, such as correlation between items 3 and 4 errors. Those authors reported that items 3 and 4 neither have adequate convergent validity nor strong enough factorial weights. Conversely, Lin et al. ${ }^{36}$ and

Table 2 - Psychometric properties of the World Health Organization Quality of Life Instrument-Abbreviated version (WHOQOL-Bref) in different samples

\begin{tabular}{|c|c|c|c|c|c|c|c|c|c|c|c|c|}
\hline \multirow[b]{2}{*}{ Sample/model } & \multirow[b]{2}{*}{$\mathbf{n}$} & \multicolumn{5}{|c|}{ CFA* } & \multirow[b]{2}{*}{ IE } & \multirow[b]{2}{*}{ MI } & \multirow[b]{2}{*}{$\mathbf{r}^{2}$} & \multirow[b]{2}{*}{ AVE } & \multirow[b]{2}{*}{ CR } & \multirow[b]{2}{*}{$\mathbf{a}$} \\
\hline & & $\boldsymbol{\lambda}$ & $x^{2} / d f$ & CFI & TLI & RMSEA & & & & & & \\
\hline \multicolumn{13}{|l|}{ Brazilian patients } \\
\hline Total - 1st order & 1,120 & $0.39-0.86$ & 9.82 & 0.89 & 0.88 & 0.09 & - & - & $0.36-0.69$ & $0.31-0.57$ & $0.77-0.83$ & $0.77-0.83$ \\
\hline Total - 1st order fitted & 1,120 & $0.41-0.88$ & 7.00 & 0.93 & 0.92 & 0.07 & 8,15 & $3-4$ & $0.36-0.66$ & $0.31-0.56$ & $0.75-0.83$ & $0.75-0.83$ \\
\hline Test - 1st order fitted & 560 & $0.40-0.88$ & 3.79 & 0.93 & 0.92 & 0.07 & 8,15 & $3-4$ & $0.35-0.70$ & $0.32-0.55$ & $0.76-0.86$ & $0.75-0.82$ \\
\hline Validation - 1st order fitted & 560 & $0.36-0.87$ & 4.28 & 0.93 & 0.92 & 0.07 & 8,15 & $3-4$ & $0.37-0.62$ & $0.30-0.58$ & $0.74-0.83$ & $0.74-0.82$ \\
\hline Total - 2nd order & 1,120 & $0.41-0.88$ & 7.14 & 0.93 & 0.92 & 0.07 & 8,15 & $3-4$ & - & $0.31-0.56$ & $0.75-0.85$ & - \\
\hline \multicolumn{13}{|l|}{ Brazilian students } \\
\hline Total - 1st order & 1,398 & $0.35-0.90$ & 10.98 & 0.87 & 0.86 & 0.08 & - & - & $0.26-0.61$ & $0.27-0.53$ & $0.73-0.81$ & $0.74-0.80$ \\
\hline Total - 1st order fitted & 1,398 & $0.43-0.92$ & 7.40 & 0.94 & 0.93 & 0.07 & $8,15,3,4$ & - & $0.25-0.60$ & $0.30-0.57$ & $0.75-0.88$ & $0.74-0.80$ \\
\hline Test - 1st order fitted & 699 & $0.47-0.91$ & 4.09 & 0.93 & 0.92 & 0.07 & $8,15,3,4$ & - & $0.19-0.56$ & $0.31-0.55$ & $0.76-0.83$ & $0.75-0.78$ \\
\hline Validation - 1st order fitted & 699 & $0.38-0.92$ & 4.03 & 0.94 & 0.94 & 0.07 & $8,15,3,4$ & - & $0.31-0.63$ & $0.29-0.58$ & $0.74-0.84$ & $0.73-0.81$ \\
\hline Total - 2nd order & 1,398 & $0.43-0.92$ & 7.98 & 0.93 & 0.92 & 0.07 & $8,15,3,4$ & - & - & $0.30-0.57$ & $0.75-0.84$ & - \\
\hline \multicolumn{13}{|l|}{ Portuguese students } \\
\hline Total - 1st order & 1,165 & $0.36-0.89$ & 9.48 & 0.88 & 0.87 & 0.08 & - & - & $0.31-0.61$ & $0.32-0.54$ & $0.77-0.82$ & $0.74-0.82$ \\
\hline Total - 1st order fitted & 1,165 & $0.43-0.87$ & 8.06 & 0.92 & 0.91 & 0.08 & $8,15,3,4$ & - & $0.25-0.61$ & $0.35-0.57$ & $0.77-0.84$ & $0.74-0.82$ \\
\hline Test - 1st order fitted & 582 & $0.44-0.88$ & 4.70 & 0.92 & 0.90 & 0.08 & $8,15,3,4$ & - & $0.21-0.62$ & $0.34-0.56$ & $0.76-0.84$ & $0.74-0.82$ \\
\hline Validation - 1st order fitted & 583 & $0.43-0.90$ & 4.43 & 0.93 & 0.92 & 0.08 & $8,15,3,4$ & - & $0.30-0.59$ & $0.36-0.56$ & $0.77-0.83$ & $0.73-0.81$ \\
\hline Total - 2nd order & 1,165 & $0.43-0.89$ & 8.04 & 0.92 & 0.91 & 0.08 & $8,15,3,4$ & - & - & $0.35-0.57$ & $0.76-0.84$ & - \\
\hline \multicolumn{13}{|l|}{ Mozambican students } \\
\hline Total - 1st order & 337 & $0.02-0.80$ & 2.98 & 0.85 & 0.83 & 0.08 & - & - & $0.41-0.76$ & $0.24-0.34$ & $0.60-0.76$ & $0.65-0.74$ \\
\hline Total - 1st order fitted & 337 & $0.41-0.79$ & 2.93 & 0.91 & 0.90 & 0.08 & $3,4,8,9,11,26$ & - & $0.35-0.79$ & $0.33-0.46$ & $0.64-0.80$ & $0.65-0.72$ \\
\hline Test - 1st order fitted & 168 & $0.37-0.77$ & 1.87 & 0.91 & 0.90 & 0.07 & $3,4,8,9,11,26$ & - & $0.29-0.79$ & $0.26-0.48$ & $0.57-0.80$ & $0.54-0.74$ \\
\hline Validation - 1st order fitted & 169 & $0.30-0.85$ & 2.10 & 0.91 & 0.90 & 0.08 & $3,4,8,9,11,26$ & - & $0.41-0.83$ & $0.25-0.47$ & $0.65-.081$ & $0.65-0.82$ \\
\hline Total - 2nd order & 337 & $0.41-0.79$ & 2.90 & 0.92 & 0.90 & 0.07 & $3,4,8,9,11,26$ & - & - & $0.29-0.46$ & $0.64-0.80$ & \\
\hline
\end{tabular}

Invariance

Patient (test vs. validation) $\quad \Delta x^{2}: \lambda(18)=25.01, p=0.125$; Intercept $(80)=81.59, p=0.429 ;$ Covariance/residual $(62)=53.31, p=0.776$

Brazilian (test vs. validation) $\quad \Delta x^{2}: \lambda(16)=9.92, p=0.871$; Intercept $(71)=50.11, p=0.972 ;$ Covariance/residual $(55)=38.43, p=0.956$

Portuguese (test vs. validation) $\Delta x^{2}: \lambda(16)=15.11, p=0.561$; Intercept $(71)=65.27, p=0.669$; Covariance/residual $(55)=50.27, p=0.656$

Mozambican (test vs. validation) $\Delta x^{2}: \lambda(13)=12.39, p=0.496$; Intercept $(60)=55.61, p=0.637 ;$ Covariance/residual $(47)=42.58, p=0.656$ Brazil vs. Portugal $\Delta \mathrm{x}^{2}: \lambda(16)=40.77, \mathrm{p}=<0.001 ;$ Intercept $(72)=336.26, \mathrm{p}<0.001 ;$ Covariance/residual $(56)=348.63, \mathrm{p}<0.001$

$a=$ ordinal alpha calculated on the item polychoric correlations matrix; $\lambda=$ factorial weight; $\mathrm{X}^{2} / \mathrm{df}=$ chi-square by degrees of freedom; AVE $=$ average variance extracted; CFA = confirmatory factor analysis; CFI = comparative fit index; $C R=$ composite reliability; IE = items excluded; MI = indicates correlating the residuals of two items; $r^{2}=$ squared correlation between factors; RMSEA = root mean square error of approximation; TLI = Tucker-Lewis index. 
Chang \& Lin ${ }^{37}$ suggested that negatively worded items $(3,4$, and 26$)$ in the WHOQOL-Bref may fit poorly to the sample because of wording effects. Thus, in our study, items 3 and 4 were deleted to assess the quality of life in non-patients, as they specifically deal with physical pain and medical treatment. However, we chose to use these items in the sample of Brazilian patients because the content is important to this population.

Regarding the factorial model of the WHOQOL-Bref, some studies ${ }^{10,17-19}$ found structures different from the original proposal; however, in the present study, we used the WHOQOL Group's proposal of four first-order factors and one second-order factor. The second-order factor (quality of life) was fitted to all the samples of this study. The inclusion of the second-order factor has also been supported by other studies ${ }^{8,16,18}$ and represents an interesting way of assessing the quality of life of individuals, mainly in studies that seek to evaluate the impact of different aspects on quality of life as a central construct evaluated by different factors. Furthermore, our results may have implications to both future studies and professionals in the area of quality of life because we showed valid and reliable structures for the WHOQOL-Bref that can be used with individuals with similar characteristics to our samples, since the psychometric properties of an instrument can be influenced by sample characteristics.

Another important point about the psychometric properties of the WHOQOL-Bref in our samples was the lack of convergent and discriminant validity of the first-order factors and their items. Skevington et al. ${ }^{10}$ reported that some WHOQOL-Bref items present high correlations with more than one factor or converge to a different factor, especially when the instrument is applied to small samples. Furthermore, when we assessed the reliability of the WHOQOL-Bref in relation to our samples, we found adequate values of $\mathrm{CR}$ and a for all samples except for the Mozambican sample. However, it must be pointed out that the Mozambican sample is relatively small compared to those from other countries. Studies carried out by other researchers also corroborate our results about adequate reliability ${ }^{8,18}$ and poor psychometric properties when dealing with smallsized samples, ${ }^{10}$ such as the Mozambican sample. These results strengthen the evidence that the questionnaire should be carefully analyzed according to each sample and that small modifications or the addition of a secondorder factor may be interesting to ensure a reliable estimate of the quality of life.

In the last stage of the study, we evaluated the invariance of the WHOQOL-Bref in independent subsamples (test vs. validation) and in transnational samples (Brazil vs. Portugal). The strong invariance of the fitted models of the WHOQOL-Bref in all samples shows that the models were adequate when replicated in different subsamples. The noninvariance between Brazil and Portugal reveals that there are cultural differences between the countries with regard to the construction of the quality of life construct. These differences can also be attributed to the distinct characteristics of the samples. BenítezBorrego et al. ${ }^{21}$ showed that there are extensive cultural differences when using the WHOQOL-Bref with different populations (even in populations with the same language), and that the interpretation of each item may vary from country to country. Thus, they highlight the importance of evaluating this instrument with different populations with the aim of using adequate models to assess quality of life in different cultures. We showed different models of the WHOQOLBref that can be used with Brazilian patients, as well as with Brazilian, Portuguese, and Mozambican students with characteristics similar to those of our samples.

In summary, our study presented the psychometric properties of the WHOQOL-Bref for Portuguese-speaking adults from three different countries. The fitted models of the WHOQOL-Bref showed adequate factorial validity and invariance in independent subsamples. The transnational non-invariance of the WHOQOL-Bref shows the influence of culture on the operationalization of the quality of life construct, which must be accounted for when using the instrument in different countries - even in countries speaking the same language. We hope that this research may raise the awareness of the professionals and researchers in the field to the importance of assessing the psychometric properties of the WHOQOL-Bref in different samples and encourage future transnational studies.

This study has some limitations regarding the patient sample, choice of institutions, and the Mozambican sample size. The patient sample comprised only Brazilians, because it was not possible to collect data from patients in the other countries. Thus, we suggest that new studies be carried out with samples of Portuguese and Mozambican patients so that results can be compared to ours. Another limitation of this study refers to the non-probabilistic choice of institutions for data collection, which makes it more difficult to generalize the results. With regard to the Mozambican sample size, unfortunately we did not achieve a large sample size, which may have interfered with the factorial structure of the WHOQOLBref fit to this sample. Therefore, we recommend a new study using a larger Mozambican sample to verify whether the model found in our study was influenced by sample size or if it is a common characteristic of 
Mozambican individuals. Furthermore, we encourage future studies to evaluate the linguistic validity of the Portuguese version of the WHOQOL-Bref, as we did not evaluate this step.

\section{Acknowledgments}

The authors thank Fundação de Amparo à Pesquisa do Estado de São Paulo (FAPESP; grants 2014/030932, 2014/00874-3, 2014/17624-0 and 2015/002287), Conselho Nacional de Desenvolvimento Científico e Tecnológico (CNPq; grants 142315/2014-1 and 301611/2015-7), and Coordenação de Aperfeiçoamento de Pessoal de Nível Superior (CAPES) for financing the study.

The authors are grateful to Profs. Afonso Cavaco, Filipa Costa, José Santos, Maria Caramona, Maria Costa, Maria Vinagre, and Célia Simão Oliveira, as well as students Andreia Caldeira, Fernanda Maurício, Moema de Souza Santana, and Bianca Martins, who contributed to data collection.

\section{Disclosure}

No conflicts of interest declared concerning the publication of this article.

\section{References}

1. Fayers PM, Machin D. Quality of life: assessment, analysis, and interpretation. Chichester: John Wiley \& Sons Ltd; 2000.

2. Seidl EMF, Zannon CMLC. Quality of life and health: conceptual and methodological issues. Cad Saude Publica. 2004;20:580-8.

3. WHOQOL Group. The World Health Organization qualify of life assessment (WHOQOL): position paper from the World Health Organization. Soc Sci Med. 1995;41:1403-9.

4. Fleck MPA, Leal OF, Louzada S, Xavier M, Chachamovich E, Vieira G, et al. Development of the Portuguese version of the OMS evaluation instrument of quality of life. Rev Bras Psiquiatr. 1999;21:19-28.

5. WHOQOL Group. Development of the WHOQOL: rationale and current status. Int J Ment Health. 1994;23:24-56.

6. Bampi LNS, Baraldi S, Guilhem D, Lino MM, Campos ACO. Quality of life of health sciences students: similarities and differences. J Nurs. 2016;10:2589-94

7. Colbourn T, Masache G, Skordis-Worrall J. Development, reliability and validity of the Chichewa WHOQOL-BREF in adults in Lilongwe, Malawi. BMC Res Notes. 2012;5:346.

8. Fu TS, Tuan YC, Yen MY, Wu WH, Huang CW, Chen WT, et al. Psychometric properties of the World Health Organization Quality Of Life Assessment-Brief in methadone patients: a validation study in northern Taiwan. Harm Reduct J. 2013;10:37.

9. Ohaeri JU, Awadalla AW, El-Abassi AH, Jacob A. Confirmatory factor analytical study of the WHOQOL-Bref: experience with Sudanese general population and psychiatric samples. BMC Med Res Methodol. 2007;1:1-9.

10. Skevington SM, Lotfy M, Connell KAO. The World Health Organization's WHOQOL-BREF quality of life assessment: psychometric properties and results of the international field trial
A Report from the WHOQOL Group. Qual Life Res. 2004;13:299310 .

11. Bullinger $M$, Anderson $R$, Cella $D$. Developing anda evaluating cross-cultural instruments from minimum requirements to optimal models. Qual Life Res. 1993;2:451-9.

12. WHOQOL Group. The World Health Organization Quality of Life Assessment (WHOQOL): Development and general psychometric properties. Soc Sci Med. 1998;46:1569-85.

13. WHOQOL Group. Development of the World Health Organization WHOQOL-BREF quality of life assessment. Psychol Med. 1998;28:551-8.

14. Shawver Z, Griffith JD, Adams LT, Evans JV, Benchoff B, Sargent R. An examination of the WHOQOL-BREF using four popular data collection methods. Comput Human Behav. 2016;55:446-54.

15. Singh K, Junnarkar M. Validation and effect of demographic variables on perceived quality of life by adolescents. Asian J Psychiat. 2014;12:88-94.

16. Yoshitake N, Sun Y, Sugawara M, Matsumoto S, Sakai A, Takaoka J, et al. The psychometric properties of th WHOQOL-BREF in Japanese couples. Health Psychol Open. 2015;2:1-9.

17. Najafi M, Sheikhvatan M, Montazeri A, Sheikhfatollahi M. Factor structure of the World Health Organization's Quality of Life Questionnaire-BREF in patients with coronary artery disease. Int J Prev Med. 2013;4:1052-8.

18. Yao G, Chung CW, Yu CF, Wang JD. Development and verification of validity and reliability of the WHOQOL-BREF taiwan version. J Formos Med Assoc. 2002;101:342-51.

19. Oliveira SE, Carvalho H, Esteves F. Toward an understanding of the quality of life construct: validity and reliability of the WHOQOLBref in a psychiatric sample. Psychiat Res. 2016;244:37-44.

20. Silva WR, Costa D, Pimenta F, Maroco J, Campos JADB. Psychometric evaluation of a unified Portuguese-language version of the Body Shape Questionnaire in female university students. Cad Saude Publica. 2016;32:e00133715.

21. Benítez-Borrego S, Mancho-Fora N, Farràs-Permanyer L, UrzúaMorales A, Guàrdia-Olmos J. Differential item functioning of WHOQOL-BREF in nine Iberoamerican countries. Rev Iberoam Psicol Salud. 2016;7:51-9.

22. Yao G, Wu C. Similarities and differences among the Taiwan, China, and Hong-Kong versions of the WHOQOL questionnaire. Soc Indic Res. 2009;91:78-98.

23. Fleck MPA, Louzada S, Xavier M, Chachamovich E, Vieira G, Santos $L$, et al. Aplicação da versão em português do instrumento abreviado de avaliação da qualidade de vida "WHOQOL-bref". Rev Saude Publica. 2000;34:178-83.

24. Vaz Serra A, Canavarro MC, Simões MR, Pereira M, Gameiro S, Quartilho $\mathrm{MJ}$, et al. Estudos psicométricos do instrumento de avaliação da qualidade de vida da Organização Mundial de Saúde (WHOQOL-Bref) para português de Portugal. Psiquiatr Clin. 2006:27:41-9.

25. Hair JF, Black WC, Babin B, Anderson RE, Tatham RL. Multivariate data analysis. 6th ed. Upper Saddle River: Prentice Hall; 2005.

26. Associação Brasileira de Empresas de Pesquisa (ABEP). Critério Brasil. 2015 [cited May 16 2017]. http://www.abep.org/criteriobrasil

27. Marôco J. Análise de equações estruturais. $2^{a}$ ed. Lisboa: ReportNumber; 2014.

28. Kline RB. Principles and practice of structural equation modeling. New York: The Guilford Press; 1998.

29. Hair Jr JF, Black WC, Babin B, Anderson RE. Multivariate data analysis. 7th ed. Upper Saddle River: Prentice Hall; 2009.

30. Fornell C, Larcker DF. Evaluating structural equation models with unobservable variables and measurement error. J Marketing Res. 1981:18:39-50.

31. Gadermann AM, Guhn M, Zumbo BD. Estimating ordinal reliability for Likert-type and ordinal item response data: A conceptual, empirical, and practical guide. Pratic Assess Res Eval. 2012;17:113.

32. Marôco J, Garcia-Marques T. Qual a fiabilidade do alfa de Cronbach? Questões antigas e soluções modernas? Laboratório de Psicologia. 2006;4:65-90.

33. Kaplan D. Structural equation modeling: foundations and extensions. Thousand Oaks: Sage Publications; 2000.

34. Kluthcovsky ACGC, Kluthcovsky FA. O WHOQOL-bref, um instrumento para avaliar qualidade de vida: uma revisão sistemática. Rev Psiquiatr Rio Gd Sul. 2009;31:1-12.

35. Najafi M, Sheikhvatan M, Montazeri A, Abbasi SH, Sheikhfatollahi M. Quality of life in coronary artery disease: SF-36 compared to WHOQOL-BREF. J Tehran Heart Cent. 2008;3:101-6. 
36. Lin CY, Yang SC, Lai WW, Su WC, Wang JD. Rasch models suggested the satisfactory psychometric properties of the World Health Organization Quality of Life-Brief among lung cancer patients. J Health Psychol. 2017;22:397-408.

37. Chang KC, Lin CY. Effects of publicly funded and quality of life on attendance rate among methadone maintenance treatment patients in Taiwan: an 18-month follow-up study. Harm Reduct J. 2015;40:1-7.

\section{Correspondence:}

Juliana Alvares Duarte Bonini Campos

Departamento de Alimentos e Nutrição

Faculdade de Ciências Farmacêuticas

Universidade Estadual Paulista - UNESP

Rodovia Araraquara Jaú, km 01, Campos Ville

14800-903 - Araraquara, SP - Brazil

Tel. : +55 (16) 33016935

E-mail: jucampos@fcfar.unesp.br 